\title{
The PROP1 2-Base Pair Deletion Is a Common Cause of Combined Pituitary Hormone Deficiency*
}

\author{
JOY D. COGAN, WEI WU, JOHN A. PHILLIPS III, IVO J. P. ARNHOLD, \\ ANA AGAPITO, OLGA V. FOFANOVA, MARIA GERALDA F. OSORIO, \\ IFFET BIRCAN, ADOLFO MORENO, AND BERENICE B. MENDONCA \\ Department of Pediatrics, Vanderbilt University School of Medicine (J.D.C., J.A.P., A.M.), Nashville, \\ Tennessee 37232-2578; Howard Hughes Medical Institute, University of California-San Diego (W.W.), \\ La Jolla, California 92093-0648; the Division of Endocrinology, Hospital das Clinicas (I.J.P.A., \\ M.G.F.O., B.B.M.), Sao Paulo, Brazil; the Department of Endocrinology, Hospital De Curry Cabral \\ (A.A.), Lisbon, Portugal; the Department of Pediatrics, All-Russian Research Center for Endocrinology \\ (O.V.F.), Moscow, Russia; and the Department of Pediatrics, Akdeniz University School of Medicine \\ (I.B.), Antalya, Turkey
}

\begin{abstract}
Combined pituitary hormone deficiency (CPHD) has an incidence of approximately 1 in 8000 births. Although the proportion of familial CPHD cases is unknown, about $10 \%$ have an affected first degree relative. We have recently reported three mutations in the PROP1 gene that cause CPHD in human subjects. We report here the frequency of one of these mutations, a 301-302delAG deletion in exon 2 of PROP1, in 10 independently ascertained CPHD kindreds and 21 sporadic cases of CPHD from 8 different countries. Our results show that 55\% (11 of 20) of PROP1 alleles have the 301-302delAG deletion in familial CPHD cases. Interestingly, although only $12 \%$ (5 of 42 ) of
\end{abstract}

the PROP1 alleles of our 21 sporadic cases were 301-302delAG, the frequency of this allele (in 20 of 21 of the sporadic subjects given TRH stimulation tests) was 50\% (3 of 6) and 0\% ( 0 of 34) in the CPHD cases with pituitary and hypothalamic defects, respectively. Using whole genome radiation hybrid analysis, we localized the PROP1 gene to the distal end of chromosome $5 q$ and identified a tightly linked polymorphic marker, D5S408, which can be used in segregation studies. Analysis of this marker in affected subjects with the 301-302delAG deletion suggests that rather than being inherited from a common founder, the 301-302delAG may be a recurring mutation. (J Clin Endocrinol Metab 83: 3346-3349, 1998)
C ONGENITAL defects of the pituitary include autosomal recessive, autosomal dominant, and X-linked forms which have combined deficiencies of anterior pituitary tropic hormones (CPHD). In CPHD, deficiencies of ACTH, gonadotropin, GH, PRL, and/or TSH occur, causing growth failure and altered sexual development, including small genitalia in males, delayed or incomplete secondary sexual development with infertility, and shortened life expectancy (1-3).

There are now two genes known to cause CPHD in humans: PIT1 and Prophet of PIT1 (PROP1). Although the number of families with reported PIT1 defects is small, a recent report suggests that a significant proportion of familial CPHD cases may have PROP1 defects (4). Furthermore, three of four of the CPHD families reported had a 2-bp deletion (301-302delAG) in exon 2 of PROP1, suggesting that the 301-302delAG mutation may be a major cause of CPHD.

To determine the frequency of the 301-302delAG deletion in CPHD subjects we screened all of our familial $(n=10)$ and sporadic $(n=21)$ CPHD cases. Included in the familial stud-

Received April 6, 1998. Revision received June 2, 1998. Accepted June 12, 1998.

Address all correspondence and requests for reprints to: Dr. Joy D. Cogan, Department of Pediatrics, Vanderbilt University School of Medicine, Nashville, Tennessee 37232-2578.

* This work was supported by NIH Grant DK-52312 (to J.D.C.), the Genentech Foundation for Growth and Development (to J.D.C. and J.A.P.), FAPESP 1996/1738-6 (to M.G.O.), and a Center Grant from the NCI (CA-68485). ies are three kindreds (see 6, 7, and 9 in Fig. 1), who have been reported previously (4). We also identified a polymorphic marker genetically linked to the PROP1 gene and used it to determine whether the 301-302delAG deletions were inherited from a common founder or arose from recurring mutations.

\section{Subjects}

\section{Subjects and Methods}

We studied DNAs from 10 nonrelated kindreds with multiple individuals with CPHD and 21 sporadic CPHD cases from 8 different countries. Affected subjects were diagnosed with CPHD by their own endocrinologists. Diagnosis was based on clinical and biochemical studies that documented deficiencies of multiple pituitary tropic hormones, including GH. Three of the kindreds were of Russian ancestry, and the 7 remaining kindreds studied were of Brazilian, Turkish, Portuguese, Austrian, Venezuelan, Swiss, and European ancestry (see Fig. 1) $(4,5)$. We also studied 20 sporadic CPHD cases from Brazil and 1 sporadic case from Russia.

In 20 of 21 sporadic subjects, TRH stimulation tests were performed using $200 \mu \mathrm{g}$ TRH, iv. Blood samples for TSH levels were drawn at 0 , $15,30,45,60,90$, and $120 \mathrm{~min}$ after TRH injection (see Table 1 ). TSH levels were determined by immunoenzymatic assay (Baxter, Stone Mountain, GA). PRL levels were measured by immunofluorometric assay before (basal) and after (peak) TRH stimulation (DELFIA, Wallac, Finland).

PCR amplification of genomic DNA, restriction endonuclease detection, and DNA sequencing of mutation

Exon 2 of the PROP1 genes of each affected subject were PCR amplified. Genomic DNA (400 ng) was added to a $50-\mu \mathrm{L}$ reaction mixture of $10 \mathrm{mmol} / \mathrm{L}$ Tris- $\mathrm{HCl}$ (pH 8.3), $1.5 \mathrm{mmol} / \mathrm{L} \mathrm{MgCl}_{2}, 25 \mathrm{mmol} / \mathrm{L} \mathrm{KCl}$, 


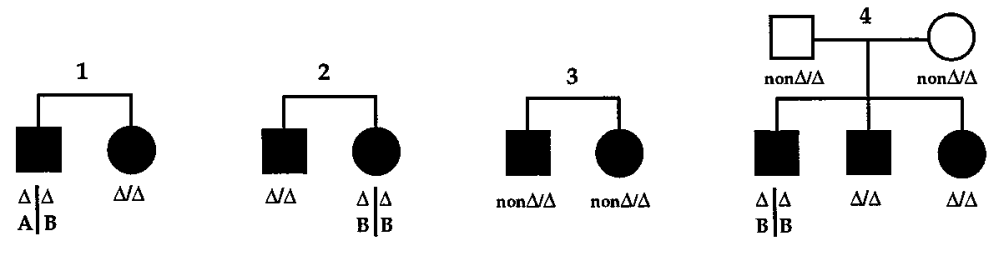

FIG. 1. Schematic drawings of CPHD kindreds from Russia (1-3), Portugal (4), Austria (5), Europe (6), Brazil (7), Venezuela (8), Switzerland (9), and Turkey (10). Affected males and females are indicated by solid squares and circles, respectively. The 301302delAG $(\Delta)$ vs. non301-302delAG (non $\Delta$ ) genotypes (see Figs. 2 and 3 ) and D5S408 A-E alleles (see Fig. 4) are shown below individual symbols.
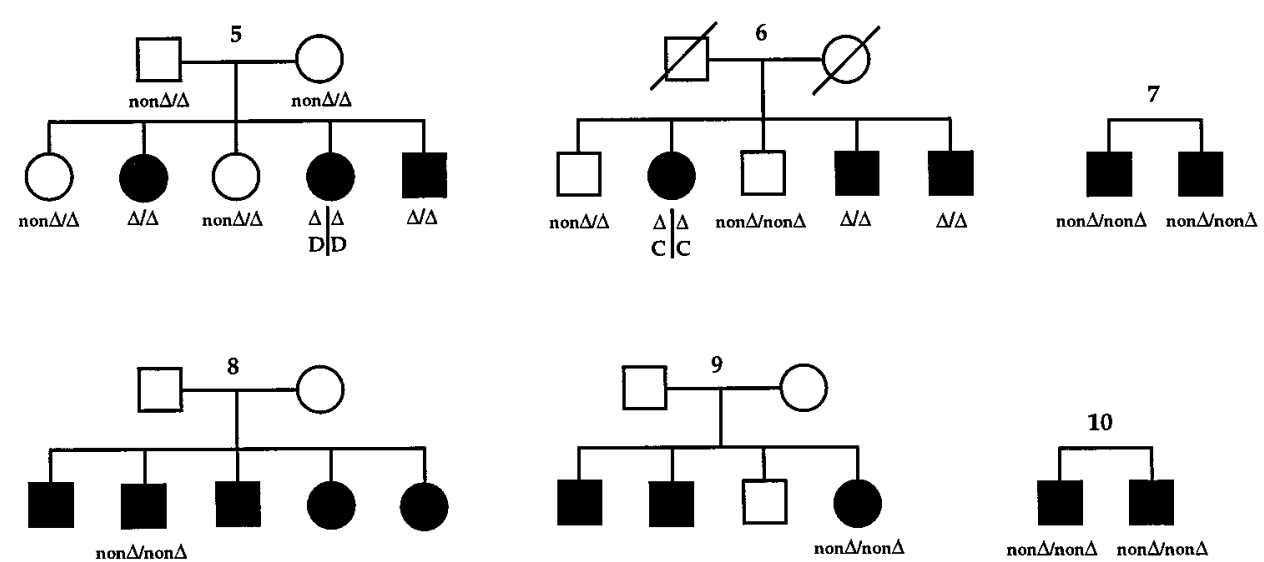

TABLE 1. TRH stimulation test results on sporadic CPHD subjects with PROP1 301-302delAG

\begin{tabular}{|c|c|c|c|c|c|c|c|c|c|c|}
\hline \multirow{2}{*}{ Subject no. } & \multirow{2}{*}{$\Delta / \mathrm{N}$} & \multicolumn{7}{|c|}{$\mathrm{TSH}(\mathrm{mU} / \mathrm{L})^{a}$ after TRH } & \multicolumn{2}{|c|}{ PRL $(\mathrm{ng} / \mathrm{mL})^{b}$} \\
\hline & & $0 \mathrm{~min}$ & $15 \mathrm{~min}$ & $30 \mathrm{~min}$ & $45 \mathrm{~min}$ & $60 \mathrm{~min}$ & $90 \min$ & $120 \mathrm{~min}$ & Basal & Peak \\
\hline 1 & $\Delta / \Delta$ & 1.5 & 3.3 & 4.3 & 4.1 & 3.6 & 2.8 & ND & 1.4 & 5.6 \\
\hline 2 & $\Delta / \mathrm{N}$ & 1.4 & 6.4 & 5.1 & 4.4 & 3.8 & 2.3 & 2.0 & 0.82 & 2.7 \\
\hline 3 & $\mathrm{~N} / \mathrm{N}$ & 0.2 & 0.3 & ND & 0.4 & 0.2 & 0.2 & 0.2 & 1.0 & 3.2 \\
\hline 4 & $\Delta / \Delta$ & ND & ND & ND & ND & ND & ND & ND & ND & ND \\
\hline
\end{tabular}

${ }^{a}$ Normal basal and peak TSH responses are $1.8 \pm 0.8$ and $11.1 \pm 0.8$ and $11.1 \pm 5.5 \mathrm{mU} / \mathrm{L}$.

${ }^{b}$ Normal basal and peak PRL responses are $12 \pm 11.2 \mathrm{ng} / \mathrm{mL}$ (mean $\pm \mathrm{SD} ;$ range, $\left.3.5-39.3 \mathrm{ng} / \mathrm{mL}\right)$ and $58.7 \pm 27 \mathrm{ng} / \mathrm{mL}(\mathrm{mean} \pm 1 \mathrm{sD} ; \mathrm{range}$, $20-116 \mathrm{ng} / \mathrm{mL}$ ), respectively.

$200 \mathrm{mmol} / \mathrm{L}$ of each deoxy (d)-NTP, $15 \mathrm{pmol}$ of each primer, and 1.75 U AmpliTaq Gold DNA polymerase (Perkin-Elmer, Branchburg, NJ). The forward and reverse primers were $5^{\prime}$-GACAGGCACATGTGGTCCA-3' and 5'-AGGCCTGTGTCTGGTGACCA-3', respectively. The PCR reaction mixture was denatured for $10 \mathrm{~min}$ at $94 \mathrm{C}$ and cycled 34 times ( $94 \mathrm{C}$ for $30 \mathrm{~s}, 55 \mathrm{C}$ for $30 \mathrm{~s}$, and $72 \mathrm{C}$ for $30 \mathrm{~s}$ ), followed by a 10-min extension at $72 \mathrm{C}$. The resulting PROP1 PCR products (416 or $414 \mathrm{bp}$ ) were cleaned by filtration with a Microcon-50 microconcentrator (Amicon Corp., Danvers, MA) and used as templates for restriction endonuclease digestion and direct sequencing. Aliquots of the PROP1 PCR products were digested with $B c g I$ at $37 \mathrm{C}$ for $4 \mathrm{~h}$, and the fragments were separated on a 3.5\% Metaphor agarose (FMC BioProducts, Rockland, ME) gel and visualized by ethidium bromide staining (Fig. 2). Products with altered $B c g I$ restriction patterns were then sequenced by the dideoxy method using the Thermo Sequenase cycle sequencing system (Amersham Life Science, Cleveland, OH; Fig. 3).

\section{Radiation hybrid (RH) mapping}

RH mapping was performed using the Genebridge 4 (GB4) and the Stanford (G3) whole genome RH panels (Research Genetics, Huntsville, $\mathrm{AL}$ ), which consist of 93 and 83 genomic DNAs from human-on-hamster somatic cell lines, respectively $(6,7)$. Genomic DNAs $(25 \mathrm{ng})$ were added to $10-\mu \mathrm{L}$ PCR reaction mixtures of $10 \mathrm{mmol} / \mathrm{L}$ Tris- $\mathrm{HCl}(\mathrm{pH} 8.3), 1.5$ $\mathrm{mmol} / \mathrm{L} \mathrm{MgCl} 2,25 \mathrm{mmol} / \mathrm{L} \mathrm{KCl}, 200 \mathrm{mmol} / \mathrm{L}$ of each dNTP, $3 \mathrm{pmol}$ of each primer (see primer sequences above), and $0.35 \mathrm{U}$ AmpliTaq Gold DNA polymerase (Perkin-Elmer). The PCR reactions were then cycled as described in the above section, and the 416-bp products were separated on a $2 \%$ agarose gel and visualized by ethidium bromide staining. The GB4 and G3 RH results were analyzed by the software programs on the Whitehead Institute/MIT Center for Genome Research (http:// www-genome.wi.mit.edu/) and the Stanford Human Genome Center (http://shgc-www.stanford.edu/) web pages, respectively.

\section{Microsatellite studies}

Genomic DNAs were genotyped for a dinucleotide repeat polymorphism (D5S408) linked to the PROP1 gene. Genomic DNA (200 ng) was added to a $50-\mu \mathrm{L}$ reaction mixture of $10 \mathrm{mmol} / \mathrm{L}$ Tris $-\mathrm{HCl}(\mathrm{pH} 8.3), 1.5$ $\mathrm{mmol} / \mathrm{L} \mathrm{MgCl}_{2}, 25 \mathrm{mmol} / \mathrm{L} \mathrm{KCl}, 200 \mathrm{mmol} / \mathrm{L} / \mathrm{L}$ of each dNTP, $1.5 \mathrm{pmol}$ of $5^{\prime}$-end labeled forward oligonucleotide primer, 1.5 pmol reverse oligonucleotide primer, and $2.5 \mathrm{U} \mathrm{Taq}$ polymerase (Life Technologies, Gaithersburg, MD). The forward and reverse primers were 5 '-ACAACTTCCAACCCTGAGAT-3' and 5'-ACTGTGCCTAGCCTTCATTT-3', respectively. The PCR reaction mixture was denatured for $3 \mathrm{~min}$ at $94 \mathrm{C}$ and cycled 32 times ( $94 \mathrm{C}$ for $30 \mathrm{~s}, 55 \mathrm{C}$ for $30 \mathrm{~s}$, and $72 \mathrm{C}$ for $30 \mathrm{~s}$ ), followed by a $10-\mathrm{min}$ extension at $72 \mathrm{C}$. The products were separated on a $6 \%$ denaturing polyacrylamide gel and visualized by autoradiography (Fig. 4).

\section{Results}

\section{Restriction endonuclease detection of the PROP1 301-302delAG mutation}

The exon 2 301-302delAG deletion described by Wu et al. creates a $B c g I$ restriction endonuclease site that was used to screen the PCR products, derived from exon 2 of the PROP1 genes, of a series of CPHD subjects for the 2-bp deletion. Digestion of the 414-bp PROP1 PCR products from affected subjects with the 301-302delAG allele generated 3 fragments 
of 247, 133, and $34 \mathrm{bp}$ (see Fig. 2). The presence of the 414-bp fragment as well as the 247- and 133-bp fragments derived from DNAs of some CPHD samples indicates that they are heterozygous for 301-302delAG. Of the 10 familial cases studied, 5 were homozygous (families 1, 2, 4, 5, and 6) and 1 was heterozygous (family 3) for 301-302delAG (see Fig. 1). Of the 21 sporadic cases, 2 were homozygous and 1 was heterozygous for 301-302delAG. The results of the BcgI re-

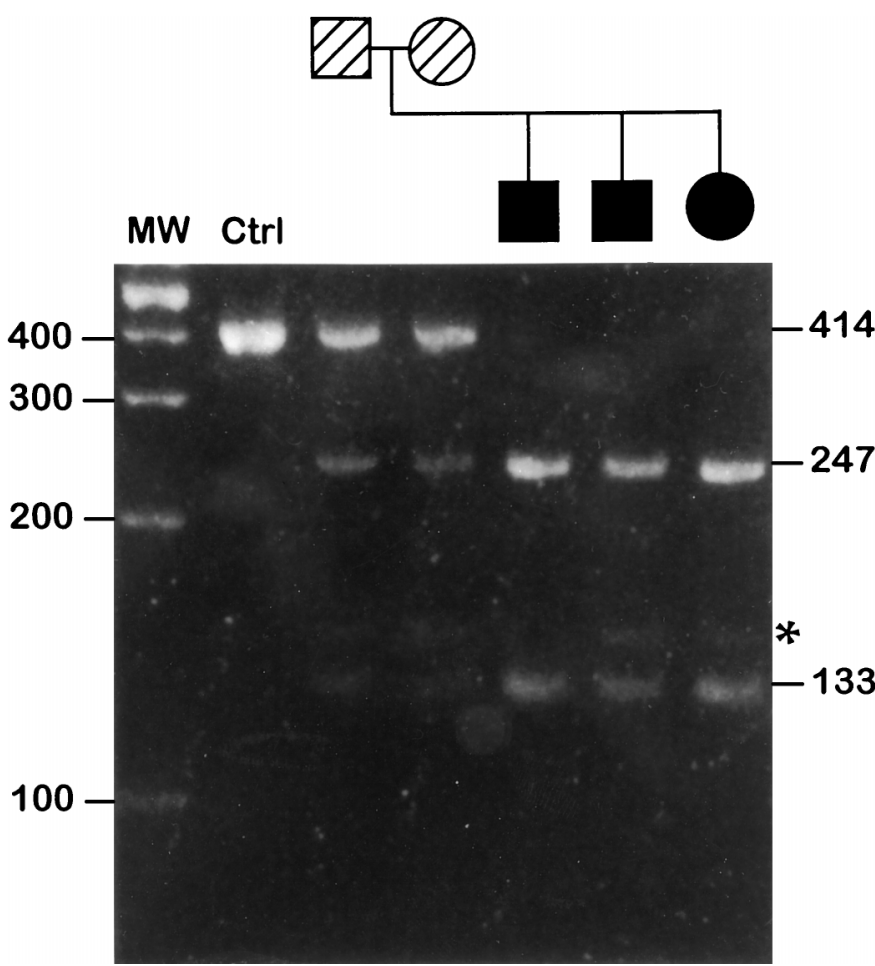

FIG. 2. Electrophoretic analysis of PCR amplification products of subjects (kindred 4) after digestion with BcgI. The asterisk shows the size of an artifactual PCR product that was seen in most products before and after digestion with BcgI. MW, Mol wt standard; Ctrl, unaffected control. striction endonuclease digest were confirmed by DNA sequencing of the PROP1 PCR products (see Fig. 3). Analysis of PROP1 PCR products from 69 nonrelated controls (CEPH panel of DNAs) did not detect any 301-302delAG alleles (data not shown).

\section{RH mapping of PROP1}

The GB4 and G3 human whole genome RH panels were analyzed to determine the chromosomal location of the PROP1 gene and to identify nearby polymorphic markers that could be used in segregation studies of CPHD families $(6,7)$. The results of our analysis placed PROP1 on the distal end of chromosome $5 q, 9.76 \mathrm{cR}(\sim 2.6 \mathrm{Mb})$ below WI-6737 and $6.62 \mathrm{cR}(\sim 200 \mathrm{~kb})$ from SHGC-4669 for the GB4 and G3 panels, respectively. Using the Whitehead and Stanford RH maps, we identified D5S408 as the nearest polymorphic marker to PROP1, and we studied its transmission pattern in 3 nonrelated CPHD kindreds with known PROP1 gene defects. The results ( 0 recombinants of 18 meioses tested) were consistent with cosegregation of the D5S408 marker and the PROP1 gene in all 3 families.

\section{Genotyping of CPHD subjects for the 301-302delAG PROP1 allele}

To determine whether 301-302delAG alleles from different CPHD subjects were derived from a single common founder mutation or arose through recurring mutations, we determined the D5S408 genotype of six nonrelated CPHD subjects (familial cases 1, 2, 4, 5, and 6 and one sporadic case; see Fig. 4). Each subject was known to be homozygous for the 301-302delAG PROP1 allele. Direct comparison of the microsatellite products from one CPHD subject from each of the five kindreds showed that the 301-302delAG PROP1 alleles of each subject were adjacent to different D5S408 alleles.

\section{Discussion}

The PROP1 301-302delAG allele was first reported in 3 of 4 familial CPHD subjects studied (2 homozygotes and 1
FIG. 3. DNA sequence analysis of the PCR products containing segments of the PROP1 alleles of a control subject and CPHD individuals whose restriction patterns indicated non-301302delAG/non-301-302delAG (control), 301-302delAG/301-302delAG (homozygotes), and 301-302delAG/non301302delAG (heterozygotes) PROP1 genotypes, respectively.
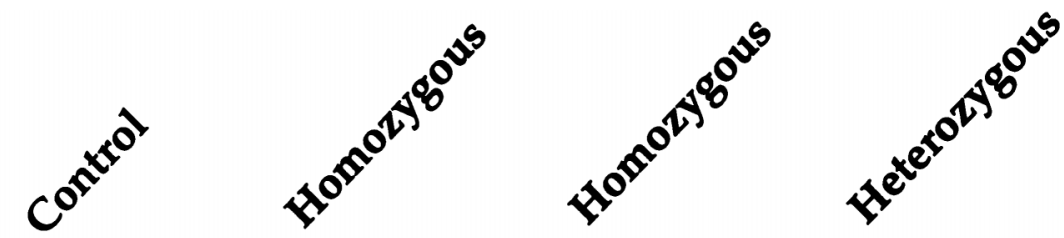

G A T C

G A T C

G A T C

G A T C

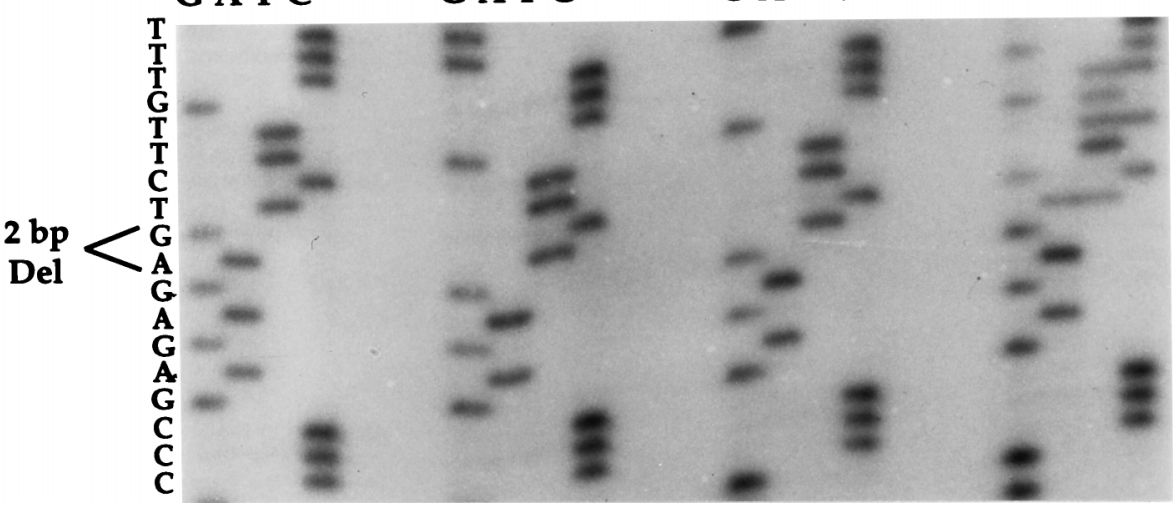




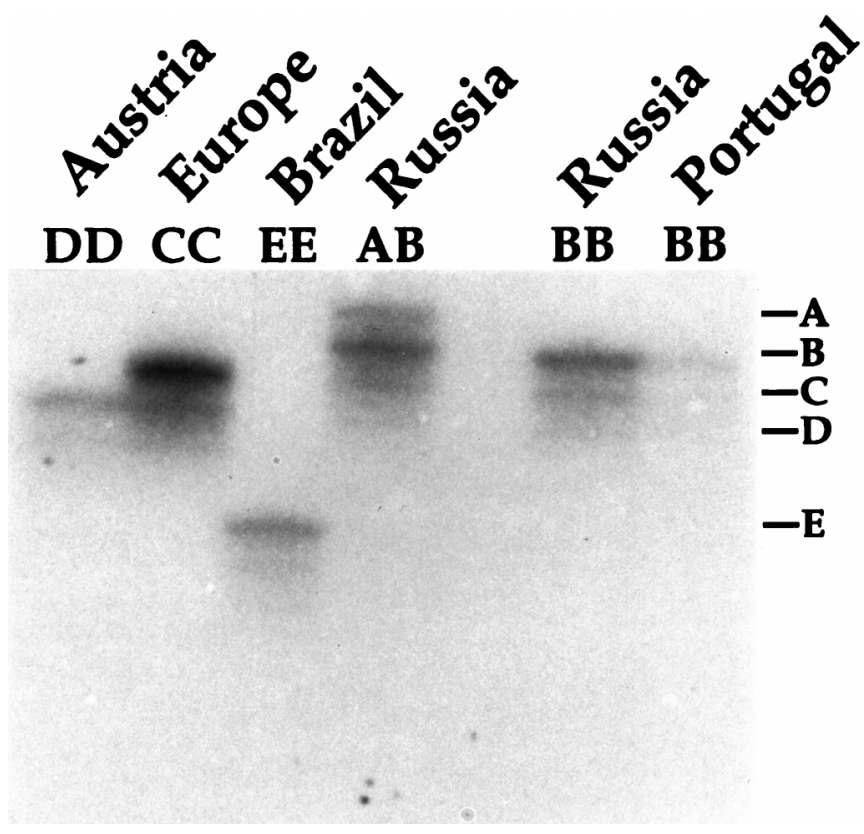

FIG. 4. Analysis of D5S408 genotypes (A-E) of 301-302delAG/301302delAG homozygotes from countries credited above (also see Fig. 1). The Brazilian sample (EE) is from a sporadic case, and the remaining samples are familial.

compound heterozygote), thus 5 of $8(62 \%)$ of the PROP1 alleles studied. This 2-bp deletion leads to a frame shift at codon 101 that results in a premature termination at codon 109. The predicted translation product is truncated with loss of the DNA-binding homeo- and C-terminal trans-activation domains of PROP1. We report here that 6 of 10 probands from independent kindreds (5 homozygous and 1 heterozygous) and 3 of 21 sporadic CPHD subjects ( 2 homozygous and 1 heterozygous) studied have the 301-302delAG PROP1 allele. Thus, our raw data show that 301-302delAG comprises approximately 55\% (11 of 20) and 12\% (5 of 42) of all PROP1 alleles in consecutive familial and sporadic CPHD cases studied, respectively.

Upon further clinical examination of our sporadic CPHD subjects we found that 20 of 21 of our subjects had been given TRH stimulation tests. Of the subjects studied, 3 of 20 had deficient peak TSH/PRL responses to TRH compared to local standards. A low normal or impaired TSH response combined with a low PRL level indicate pituitary lesions, whereas an exaggerated or delayed peak TSH response indicates hypothalamic dysfunction (8). This further subdivides our sporadic cases into a multiple hypopituitary group
(3 of 20) and a multiple hypothalamic group (17 of 20). Interestingly, 2 of 3 of the sporadic subjects in the multiple hypopituitary group were found to have 301-302delAG (1 homozygote and 1 heterozygote), making the frequency of the 301-302delAG allele 50\% (3 of 6) for these subjects. This is in agreement with normal expression of PROP1 being required for pituitary development. It is likely that subject 2 and possibly subject 3 have 1 or 2 PROP 1 alleles, respectively, that have defects other than 301-302delAG.

Our finding of different D5S408 alleles adjacent to the 301-302delAG deletions from different CPHD families suggests that these deletions probably arose as independent recurring mutations rather than being inherited from a single common founder mutation. Previous studies have shown that mutagenic errors, such as deletions and insertions, tend to occur in regions where DNA symmetry may interfere with the normal process of replication, repair, and recombination (9). Repeat sequence mutations are thought to be a common cause of human disease and can best be explained by the Streisinger slippage-repair model $(10,11)$. In this model, DNA slippage occurs when one DNA strand dissociates from the other and then reanneals in a misaligned configuration. Our findings suggest that the three tandem AG repeats (AGAGAG) of exon 2 of PROP1 may constitute a hot spot for recurring mutations that yield the 301-302delAG allele through this mechanism.

\section{References}

1. Jorgensen JOL. 1991 Human growth hormone replacement therapy: pharmacological and clinical aspects. Endocr Rev. 12:189-207.

2. Phillips III JA. 1995 Inherited defects in growth hormone synthesis and action In: Scriver CR, Beaudet AL, Sly WS, Valle D, eds. The metabolic basis of inherited disease, 6th ed. New York: McGraw-Hill; 3023-3044.

3. Rosen T, Bengtsson BA. 1990 Premature mortality due to cardiovascular disease in hypopituitarism. Lancet. 336:285-288.

4. Wu W, Cogan JD, Pfaffle RW, et al. 1998 Mutations in PROP1 cause familial combined pituitary hormone deficiency. Nat Genet. 18:147-149.

5. Fofanova OV, Takamura N, Kinoshita EI, et al. A mutational hot spot in the Prop-1 gene in Russian children with combined pituitary hormone deficiency. Pituitary. In press.

6. Walter MA, Dominique JS, Thomas P, Weissenbach J, Goodfellow PN. 1994 A method for constructing radiation hybrid maps of whole genomes. Nat Genet. 7:22-28.

7. Cox DR, Burmeister, Price ER, Kim S, Myers RM. 1990 Radiation hybrid mapping: a somatic cell genetic method for constructing high-resolution maps of mammalian chromosomes. Science. 250:245-250.

8. Cohen LE, Wondisford FE, Salvatoni A, et al. 1995 A "hot spot" in the Pit-1 gene responsible for combined pituitary hormone deficiency: clinical and molecular correlates. J Clin Endocrinol Metab. 80:679-684.

9. Sinden RR, Wells RD. 1992 DNA structure, mutation, and human genetic disease. Curr Opin Biotechnol. 3:612-622.

10. Richards RI, Sutherland GR. 1994 Simple repeat DNA is not replicated simply. Nat Genet. 6:114-116.

11. Streisinger G, Okada Y, Emrich J, et al. 1966 Frameshift mutations and the genetic code. Cold Spring Harbor Symp Quant Biol. 31:77-86. 